\title{
Restless Legs Syndrome in Patients with Chronic Obstructive Pulmonary Disease
}

\author{
Yuksel Kaplan, Handan Inonu, Ayse Yilmaz, Serpil Ocal
}

\begin{abstract}
Objective: To evaluate the prevalence of restless legs syndrome (RLS) in patients with chronic obstructive pulmonary disease (COPD) and the relationship between RLS and clinical/laboratory findings of COPD. Methods: One hundred and thirty-four COPD patients without secondary causes of RLS were included. Thirty-nine (29.1\%) patients were diagnosed with RLS and classified as Group 1. The control group consisted of 65 age-matched COPD patients without RLS. Group 1 was divided into subgroups according to the Johns Hopkins Severity (JHS) scale. Patients with a score of 0, 1, or 2 were classified as JHS 0-2 and those with a score of 3 as JHS 3. Group 1 and the control group and subgroups were compared for clinical and laboratory characteristics. Results: We found that the duration of COPD was longer and that airway obstruction, hypercapnia, and hypoxia were more evident in patients with RLS than those without. Similar differences were also detected between JHS subgroups 3 (more severe) and 0-2. Polyneuropathy frequency was significantly higher in Group 1 compared to controls. However, Group 1 subgroups showed a similar frequency of polyneuropathy. In a multivariate analysis, hypercapnia made a significant independent contribution to both JHS 0-2 and JHS 3 patients when RLS severity was set as the dependent variable. Polyneuropathy and the duration of COPD were significant independent variables for patients in the JHS 3 subgroup. Polyneuropathy was the strongest predictor for the JHS 3 patients. Conclusions: We conclude that RLS is frequent in COPD, particularly in patients with severe hypoxemia/hypercapnia and in late stages of the disease.
\end{abstract}

RÉSUMÉ: Syndrome des jambes sans repos chez les patients atteints de maladie pulmonaire obstructive chronique. Objectif : Le but de cette étude était de déterminer quelle est la prévalence du syndrome des jambes sans repos (SJSR) chez les patients atteints de maladie pulmonaire obstructive chronique (MPOC) et de définir la relation entre le SJSR et les observations cliniques et l'exploration fonctionnelle. Méthodes : Cent trente-quatre patients atteints de MPOC sans cause secondaire de SJSR ont été inclus dans l'étude. Le groupe 1 était composé de 39 patients (29,1\%) chez qui un diagnostic de SJSR avait été posé. Le groupe témoin comprenait 65 patients atteints de MPOC appariés pour l'âge, sans SJSR. Le groupe 1 était divisé en sous-groupes, selon l'échelle Johns Hopkins Severity. Le sous-groupes JHS 0-2 était composé des patients dont le score était 0, 1 ou 2 et le sousgroupe JHS 3 de ceux dont le score était 3. Les caractéristiques cliniques et fonctionnelles du groupe 1 et du groupe témoin ainsi que des sous-groupes ont été comparées. Résultats : Nous avons constaté que la durée de la MPOC était plus longue et l'obstruction des voies aériennes, l'hypercapnie et l'hypoxie étaient plus sévères chez les patients qui présentaient un SJSR que chez ceux qui n'en étaient pas atteints. Des différences similaires ont également été observées entre les sous-groupes JHS 3 (plus sévère) et JHS 0-2. La polyneuropathie était significativement plus fréquente dans le groupe 1 que dans le groupe témoin. Cependant, la fréquence de la polyneuropathie était similaire dans les sous-groupes du groupe 1. L'analyse multivariée a montré que l'hypercapnie avait une contribution indépendante significative chez les patients JHS 0-2 et JHS3 quand la sévérité du SJSR était considérée comme la variable dépendante. La polyneuropathie et la durée de la MPOC étaient des variables indépendantes significatives chez les patients du sousgroupe JHS 3. La polyneuropathie était le meilleur prédicteur chez les patients JHS 3. Conclusions : Nous concluons que le SJSR est fréquent dans la MPOC, surtout chez les patients qui présentent une hypoxémie/hypercapnie sévère et dans les stades avancés de la maladie.

Can. J. Neurol. Sci. 2008; 35: 352-357

Restless legs syndrome (RLS) is a sensorimotor disorder. The cause of RLS is unknown. Restless legs syndrome may be idiopathic or secondary to other disorders.

Idiopathic RLS appears to run in families, suggesting a genetic basis. In support of this, separate chromosomal loci have been linked to the disease in longitudinal family genetic studies, and a strong family history of RLS is more closely correlated with a younger age at onset. ${ }^{1,2}$

Secondary RLS may be associated with various diseases. Iron deficiency (with/without anemia), uremia, pregnancy, rheumatoid arthritis, peripheral neuropathy, radicul-opathy, myelopathy, spinal cord compression, multiple sclerosis, Parkinsons disease, spinocereballar ataxia, caffeine, and alcohol, metoclopramide, neuroleptics, tricyclic antidepressants, sero-

From the Gaziosmanpasa University Faculty of Medicine, Department of Neurology (YK), Department of Pulmonary Disease (HI, AY, SO), Tokat, Turkey. Received June 26, 2007. Final Revisions Submitted March 11, 2008. Reprint requests to: Yuksel Kaplan, Cigdede Mah., Adem Yavuz sokak, Kaplan apt. No: 2, Samandag/Hatay, Turkey. 
tonin reuptake inhibitors, and certain calcium channel blockers have all been associated with secondary RLS. ${ }^{1,3}$

Chronic obstructive pulmonary disease (COPD) is characterized by progressive and irreversible airway obstruction and recurrent acute attacks. ${ }^{4}$ The frequency of RLS in patients with COPD and the relationship between RLS and the clinical/laboratory findings of COPD are unclear. Very few publications have investigated the relationship between COPD and RLS.

In 1970, Spillane et al reported eight RLS patients who suffered from COPD. ${ }^{5}$ They suggested that hypoxia, hypercapnia, or other metabolic disorders were associated with RLS in COPD patients. In a recent study by Banno et al, 218 patients with RLS (103 males, 115 females) were evaluated for accompanying etiologic factors and gender distribution. ${ }^{6}$ In this study, COPD was associated with RLS in a total of $62(28.4 \%)$ patients (27 males, 35 females). However, the authors failed to demonstrate the relationship between RLS and the clinical and laboratory indicators of COPD.

We observed many patients with COPD who complained of abnormal sensation in the extremities, particularly in the legs. This observation drew our attention to a possible link between RLS and COPD. To further explore this association, we evaluated the prevalence of RLS in a sample of patients with COPD. In addition, we compared clinical and laboratory findings for COPD patients with or without RLS.

\section{Materials And Methods}

\section{Study design}

This cross-sectional clinical study was conducted between January and December 2006. The study was performed in accordance with the Declaration of Helsinki. All patients provided written informed consent and received a detailed explanation of the study and its procedures.

\section{Patients and evaluation}

The patients were diagnosed with COPD according to the Global Initiative for Chronic Obstructive Lung Disease (GOLD) criteria in the Pulmonary Diseases Outpatient Clinic of the Medical Faculty of Gaziosmanpasa University. All patients were consecutively admitted to the Department of Pulmonary Diseases and enrolled in the study.

The inclusion criteria were as follows: $>18$ years of age, clinically stable COPD, absence of any pulmonary disease except COPD, absence of pulmonary and extrapulmonary malignancies, and absence of peripheral vascular disease.

We excluded all patients with a history of diabetes mellitus, uremia, anemia, iron deficiency, rheumatoid arthritis, pregnancy, caffeine and alcohol abuse, malnutrition, systemic disease, primary sleep disorders, neurological disorders, medications that increase RLS symptoms, or a family history of RLS.

Patients with COPD were evaluated by a neurologist. Patients without a history of neurological disorders who demonstrated signs or symptoms of nervous system involvement during this evaluation were also excluded.

Standardized laboratory tests (measurement of erythrocyte sedimentation rate, hemogram, glucose, transaminases, urea, creatinine, protein electrophoresis, vitamin B12, iron levels, urine analysis) were performed to detect diseases that might predispose to polyneuropathy (PNP) or RLS.

The diagnosis of RLS rests on clinical grounds. As there was no validated Turkish RLS diagnostic questionnaire, we used one that was prepared specifically for this study, based on the International RLS Study Group (IRLSSG) criteria. ${ }^{7}$ Disease duration (years) was recorded in diagnosed RLS patients and those patients were classified as Group 1.

The Johns Hopkins Severity scale (JHS) was used to determine the severity of RLS symptoms. Patients with RLS symptom severity of 0,1 , or 2 were classified as the JHS $0-2$ subgroup, and those with a score of 3 were classified as the JHS 3 subgroup.

The control group included age-matched COPD patients without RLS. The inclusion and exclusion criteria of the patient group were also applied to the controls.

For each patient in Group 1 and the control group, a pulmonary specialist completed a form that included demographic data like age, sex, body mass index (BMI), duration of COPD symptoms, and cigarette smoking (packs/year).

\section{Neurological examination}

Both symptomatic and asymptomatic patients in both groups underwent a detailed neurological examination.

Special care was taken to detect polyneuropathy (PNP). The following peripheral neurological examination procedures were used. The presence or absence of motor deficits was recorded for each limb. Fine touch was measured using a 5.07 Semmes-Weinstein monofilament. Position sensation was tested. Vibratory sense was evaluated using a C-128 tuning fork. Intact vibratory sensation was defined as the perception of vibration, buzzing, or tingling. Muscle stretch reflex abnormalities of the arms (biceps brachi, triceps brachii, and brachioradialis) and legs (quadriceps femoris, gastrocnemiussoleus) were recorded as absent if even reinforcing methods failed to elicit a response, and as reduced if they were less brisk compared to more proximal tendon reflexes in the same patient.

For the diagnosis of definite clinical PNP, tendon reflexes had to be absent or markedly diminished bilaterally on a proximaldistal gradient and at least one or more complete, bilateral sensory or motor deficits had to present. The decision to consider only bilateral deficits was intended to exclude cases of mononeuritis, radiculopathy, injuries, and other neurological diseases.

\section{Respiratory function tests and arterial blood gas analysis}

Respiratory function tests and arterial blood gas analysis were performed for all patients in Group 1 and the control group.

Respiratory function tests were performed using a computerized device (Jaeger APS pro), with the patients sitting upright during the tests. The best of three consecutive tests was used in the analysis. Forced expiratory volume in one second $\left(\mathrm{FEV}_{1}\right)$, forced vital capacity $(\mathrm{FVC}), \mathrm{FEV}_{1} / \mathrm{FVC}$, peak expiratory flow rate (PEF), forced expiratory flow (FEF 25-75\%) were measured.

$\mathrm{pH}$, arterial oxygen tension $\left(\mathrm{PaO}_{2}\right)$, arterial carbon dioxide tension $\left(\mathrm{PaCO}_{2}\right)$, and arterial oxygen saturation $\left(\mathrm{SaO}_{2}\right)$ were analyzed in blood samples drawn from the radial artery. 
Group 1 and the control were compared with respect to demographic data, serum iron levels, frequency of PNP, respiratory function tests, and arterial blood gases. The same parameters were also compared between subgroups JHS 0-2 and JHS 3.

\section{Statistical analysis}

The Statistical Package for the Social Sciences (SPSS, version 12) was used for all statistical analyses. Data are presented as the mean $\pm \mathrm{SD}$. We used Student's $t$ test and the Mann-Whitney $U$ test for comparison of continuous parametric variables between groups. The Fisher exact $\chi^{2}$ test was used to compare categorical variables. Multivariate stepwise logistic regression analysis was performed to identify relationships between the studied variables and RLS severity in patients with COPD. A Pearson correlation test was used to establish the relationship between the duration of RLS and COPD. $P<0.05$ was deemed statistically significant.

\section{RESULTS}

One hundred and thirty-four patients with COPD (males, 112; females, 22; mean age, $61.3 \pm 6.78$ years; range, $41-79$ years) were included in the study.

Thirty-nine $(29.1 \%)$ patients met all RLS diagnostic criteria. This group (Group 1) consisted of 5 females and 34 males.

The mean age of patients in Group 1 was $63.61 \pm 8.98$ years, and that of the remaining 95 patients was $59.55 \pm 10.83$ years $(\mathrm{t}$, 2.07; $P<0.05)$. Because age differed significantly between groups, age-matched control subjects ( \pm 3 years) were selected from the remaining 95 patients. Therefore, 6 female and 59 male COPD patients were included in the control group.

Table 1: Comparison of demographic and clinical characteristics between groups

\begin{tabular}{|c|c|c|c|}
\hline Parameters & $\begin{array}{c}\text { Group } 1 \\
(n=39)\end{array}$ & $\begin{array}{l}\text { Control group } \\
\qquad(\mathrm{n}=65)\end{array}$ & $p$ values \\
\hline Gender (male-female) & $34 / 5$ & $59 / 6$ & \\
\hline Age (years) & $63.62 \pm 8.98$ & $62.63 \pm 7.88$ & 0.560 \\
\hline $\begin{array}{l}\text { Cigarette smoking } \\
\text { (packs/year) }\end{array}$ & $34.90 \pm 33$ & $32.47 \pm 25.88$ & 0.609 \\
\hline $\begin{array}{l}\text { Duration of COPD } \\
\text { (Years) }\end{array}$ & $11.72 \pm 7.46$ & $6.38 \pm 5.53$ & 0.0001 \\
\hline Polyneuropathy & 15 & 10 & 0.002 \\
\hline $\begin{array}{l}\text { Serum iron levels } \\
(\mu \mathrm{g} / \mathrm{dl})\end{array}$ & $61.69 \pm 16.76$ & $66.43 \pm 18.32$ & 0.092 \\
\hline $\begin{array}{l}\text { Body mass index } \\
\left(\mathrm{kg} / \mathrm{m}^{2}\right)\end{array}$ & $27.45 \pm 3.43$ & $29.12 \pm 2.18$ & 0.583 \\
\hline
\end{tabular}

\section{Demographic and clinical characteristics}

No significant difference existed in age, gender, cigarette smoking (packs/year), body mass index (BMI), or serum iron levels between groups.

The mean COPD duration in Group 1 was $11.72 \pm 7.46$ years, whereas that of the control group was $6.38 \pm 5.53$ years; this difference was statistically significant $(\mathrm{z},-3.745 ; p, 0.0001)$.

In addition, PNP frequency was significantly higher in Group 1 compared to the control ( 15 versus $10 ; \chi^{2}, 12.387 ; p, 0.002$ ). The basic demographic data and clinical characteristics of the groups are described in Table 1.

The mean COPD duration was $11.72 \pm 7.46$ years, and the mean RLS duration was $5.26 \pm 8.98$ years. The Pearson correlation between these two variables was strongly significant (r, 0.817; $p, 0.001)$.

\section{Respiratory function tests and arterial blood gas analysis}

Respiratory function tests showed significantly more severe airway obstruction (FEV1, $<1.51$ ) in Group 1 compared to the control group. They were also significantly more hypoxemic and hypercapnic than patients in the control group. The results of these respiratory function tests and arterial blood gas analysis are shown in Table 2.

\section{Comparison of clinical and laboratory characteristics between subgroups}

No significant differences were observed in mean age or BMI between the subgroups of patients with RLS. In addition, both groups showed a similar frequency of PNP (8 in Group 1 versus 7 in the controls; $\left.\chi^{2}, 1.950 ; p, 0.163\right)$.
Table 2: Comparison of respiratory function and arterial blood gases between groups

\begin{tabular}{lccc}
\hline Parameters & $\begin{array}{c}\text { Group 1 } \\
(\mathrm{n}=39)\end{array}$ & $\begin{array}{c}\text { Control group } \\
(\mathrm{n}=65)\end{array}$ & $\boldsymbol{p}$ values \\
$\mathrm{FEV}_{1}(1)$ & $0.94 \pm 0.05$ & $1.63 \pm 0.24$ & 0.0001 \\
$\mathrm{FEV}_{1}(\%)$ & $33.98 \pm 2.74$ & $63.65 \pm 12.19$ & 0.0001 \\
$\mathrm{FVD}(1)$ & $2.20 \pm 0.17$ & $2.75 \pm 0.5$ & 0.0001 \\
$\mathrm{FVC}(\%)$ & $62.46 \pm 8.07$ & $73.96 \pm 3.18$ & 0.0001 \\
$\mathrm{FEV}_{1} / \mathrm{FVC}$ & $43.66 \pm 3.95$ & $59.12 \pm 4.42$ & 0.0001 \\
$\mathrm{pH}$ & $7.37 \pm 0.1$ & $7.40 \pm 0.02$ & 0.552 \\
$\mathrm{PaO}_{2}(\mathrm{mmHg})$ & $53.85 \pm 5.59$ & $76.32 \pm 7.45$ & 0.0001 \\
$\mathrm{PaCO}_{2}(\mathrm{mmHg})$ & $50.60 \pm 5.29$ & $37.56 \pm 2.59$ & 0.0001 \\
$\mathrm{O}_{2} \mathrm{saturation}(\%)$ & $85.62 \pm 3.31$ & $95.48 \pm 1.97$ & 0.0001 \\
\hline
\end{tabular}


In the JHS 3 subgroup, mean cigarette smoking was $46.92 \pm$ 47.10 packs/year, compared to $28.88 \pm 21.86$ packs/year in the JHS 0-2 subgroup; the difference between these groups was not significant $(t, 1.645 ; p, 0.109)$.

The mean duration of COPD was significantly longer for patients in subgroup JHS $3(17.31 \pm 6.63$ years) compared to subgroup JHS $0-2(8.92 \pm 6.26$ years; $t, 3.86 ; p, 0.0001)$.

The mean duration of RLS in the JHS 3 subgroup was $8.59 \pm$ 3.73 years, compared to $3.59 \pm 2.89$ years in the JHS $0-2$ subgroup; this difference was also statistically significant $(t$, $4.615 ; p, 0.0001)$. The clinical characteristics of both subgroups are presented in Table 3.

Respiratory function tests showed significantly more severe airway obstruction in the JHS 3 subgroup compared to the JHS 0-2 subgroup. Moreover, patients in the JHS 3 subgroup were significantly more hypoxemic and hypercapnic than patients in the JHS 0-2 group (Table 4).

\begin{tabular}{lccc}
$\begin{array}{l}\text { Table 3: Comparison of } \\
\text { characteristics between RLS subgroups }\end{array}$ & and & clinical \\
\hline Parameters & $\begin{array}{c}\text { JHS 0-2 } \\
(\mathrm{n}=26)\end{array}$ & $\begin{array}{c}\text { JHS 3 } \\
(\mathrm{n}=13)\end{array}$ & $\boldsymbol{p}$ values \\
& $63.23 \pm 9.90$ & $64.38 \pm 7.08$ & 0.711 \\
Age (years) & $28.88 \pm 21.86$ & $46.92 \pm 47.10$ & 0.109 \\
$\begin{array}{l}\text { Cigarette smoking } \\
\text { (packs/year) }\end{array}$ & & & \\
$\begin{array}{l}\text { Duration of COPD } \\
\text { (Years) }\end{array}$ & $8.92 \pm 6.26$ & $17.31 \pm 6.63$ & 0.0001 \\
$\begin{array}{l}\text { Duration of RLS } \\
\text { (years) }\end{array}$ & $3.59 \pm 2.89$ & $8.59 \pm 3.73$ & 0.0001 \\
$\begin{array}{l}\text { Body mass index } \\
\left.\text { (kg/m }{ }^{2}\right)\end{array}$ & $26.88 \pm 1.69$ & $28.54 \pm 5.34$ & 0.160 \\
\begin{tabular}{l} 
Polyneuropathy \\
\hline
\end{tabular} & 7 & & 0.163 \\
\hline
\end{tabular}

Multivariate stepwise logistic regression analysis was performed to detect relationships between the study variables and RLS severity in patients with COPD (Table 5). When RLS severity was a dependent variable, $\mathrm{PCO}_{2}$ made a significant independent contribution to patients in the both JHS 0-2 and JHS 3 subgroups [odds ratio (OR), 1.732; 95\% confidence interval (CI), 1.38-2.17; $p, 0.0001$ versus OR, 1.74; CI, 1.27-2.37; $p$, 0.0001 , respectively]. The presence of PNP and the duration of COPD were significant independent variables only for patients in the JHS 3 subgroup (OR, 6.417; 95\% CI, 1.78-23.12; $p, 0.004$ and OR, 1.25; CI, $1.11-1.41 ; p, 0.0001$, respectively). The PNP was the strongest predictor for patients in the JHS 3 subgroup.
Table 4: Comparison of respiratory function and arterial blood gases between RLS subgroups

\begin{tabular}{lccc}
\hline Parameters & $\begin{array}{c}\text { JHS 0-2 } \\
(\mathrm{n}=26)\end{array}$ & $\begin{array}{c}\text { JHS 3 } \\
(\mathrm{n}=13)\end{array}$ & $\boldsymbol{p}$ values \\
$\mathrm{FEV}_{1}(1)$ & $0.96 \pm 0.05$ & $0.91 \pm 0.04$ & 0.003 \\
$\mathrm{FEV}_{1}(\%)$ & $34.67 \pm 2.83$ & $32.61 \pm 2.02$ & 0.025 \\
$\mathrm{FVC}(1)$ & $2.24 \pm 0.16$ & $2.11 \pm 0.15$ & 0.026 \\
$\mathrm{FVC}(\%)$ & $66.61 \pm 5.55$ & $54.15 \pm 5.49$ & 0.0001 \\
$\mathrm{FEV}_{1} / \mathrm{FVC}$ & $44.83 \pm 3.47$ & $41.32 \pm 3.95$ & 0.007 \\
$\mathrm{pH}$ & $7.38 \pm 0.01$ & $7.36 \pm 0.02$ & 0.0001 \\
$\mathrm{PaO}_{2}(\mathrm{mmHg})$ & $55.58 \pm 5.63$ & $50.38 \pm 3.66$ & 0.005 \\
$\mathrm{PaCO}_{2}(\mathrm{mmHg})$ & $49.30 \pm 4.79$ & $53.20 \pm 5.47$ & 0.029 \\
$\mathrm{O}_{2}$ saturation $(\%)$ & $87.23 \pm 2.87$ & $82.40 \pm 1.01$ & 0.0001 \\
\hline
\end{tabular}

\section{DiscuSSION}

In the present study, the prevalence of RLS in COPD patients was investigated using the IRLSSG criteria. We also examined clinical features, respiratory function tests, and arterial blood gas analysis in patients who had both COPD and RLS.

Our first major finding was that $29.1 \%$ of COPD patients also suffered from RLS. Epidemiological studies have suggested that RLS affects $1-15 \%$ of the world's different general populations. ${ }^{1}$ A higher-than-normal prevalence (20-30\%) of RLS has been found in patients with anemia, pregnancy, uremia, neuropathy, multiple sclerosis, and rheumatoid arthritis. ${ }^{1,3,8}$ The prevalence of RLS in COPD patients in our study was higher than that in previous community-based studies. Moreover, the prevalence may be close to that observed for the diseases mentioned above.

The role of gender as a risk factor in COPD remains unclear. Most studies have shown that COPD prevelance and mortality are greater among men than women., ${ }^{9,10}$ Consistent with these data, our COPD patients consisted mainly of male patients (112 versus 22 females). Therefore, the RLS patients in our study also showed a marked preponderance of males ( 34 versus 5 females). This conflicts with a previous studies showing that the incidence of RLS in women is twice that in men. ${ }^{1}$

The second major finding was that the duration of COPD was longer and that airway obstruction, hypercapnia, and hypoxia were more evident in the patients with RLS than patients without RLS. Similar differences were observed in the JHS 3 subgroup compared to the JHS 0-2 subgroup. There was a strong, significant, positive correlation between the duration of RLS and COPD. Moreover, multivariate stepwise logistic regression analysis demonstrated that the duration of COPD was a predictor of severe RLS in COPD patients. These results indicate that RLS may occur more frequently and be of longer duration in advanced COPD patients. 
Table 5: Multivariate stepwise logistic regression predictors of RLS subgroup patients

\begin{tabular}{|c|c|c|c|c|}
\hline Variables & $\begin{array}{c}\text { JHS 0-2 } \\
\text { Odds Ratio }(95 \% \text { CI) }\end{array}$ & $p$ values & $\begin{array}{c}\text { JHS 3 } \\
\text { Odds Ratio }(95 \% \text { CI) }\end{array}$ & $p$ values \\
\hline Age & $1.009(0.955-1.06)$ & 0.759 & $1.03(0.95-1.11)$ & 0.454 \\
\hline Cigarette Smoking & $0.98(0.953-1.00)$ & 0.195 & $1.027(0.99-1.06)$ & 0.101 \\
\hline Duration of COPD & $1.07(0.993-1.16)$ & 0.073 & $1.25(1.11-1.41)$ & 0.0001 \\
\hline Body mass index & $0.85(0.690-1.06)$ & 0.173 & $1.05(0.90-1.21)$ & 0.511 \\
\hline Polyneuropathy & $2.44(0.837-7.13)$ & 0.102 & $6.41(1.78-23.12)$ & 0.004 \\
\hline $\mathrm{FEV}_{1}(1)$ & - & - & - & - \\
\hline $\mathrm{FEV}_{1}(\%)$ & - & - & $0.41(0.063-2.733)$ & 0.360 \\
\hline FVC (1) & - & - & $0.000(0.000-1504.7)$ & 0.135 \\
\hline $\mathrm{FVC}(\%)$ & - & - & - & - \\
\hline $\mathrm{FEV}_{1} / \mathrm{FVC}$ & - & - & - & - \\
\hline $\mathrm{pH}$ & $1.32(0.380-4.56)$ & 0.656 & $1.17(0.37-3.66)$ & 0.781 \\
\hline $\mathrm{PaO}_{2}$ & $0.28(0.082-0.97)$ & 0.460 & $0.003(0.00-\quad)$ & 0.990 \\
\hline $\mathrm{PaCO}_{2}$ & $1.73(1.380-2.17)$ & 0.0001 & $1.74(1.27-2.37)$ & 0.0001 \\
\hline $\mathrm{O}_{2}$ saturation $(\%)$ & - & - & $0.001(0.00-\quad)$ & 0.993 \\
\hline
\end{tabular}

We could not find any published study which has evaluated the prevalence or clinical features of RLS in COPD patients except one study. Spillane et al described eight severe RLS patients suffering from severe COPD. ${ }^{5}$ They found that all neurologic examinations were normal. In four of these patients, electroneuromyographies were normal. In addition, they did not find nervous system diseases, PNP, or peripheral vascular diseases in their patients. Spillane et al suggested that hypoxia and hypercapnia or other metabolic disorders were associated with RLS in these patients.

In our study, 15 of 39 (38.4\%) of RLS patients had definite findings of PNP, detected via neurological examination, and this rate was significantly higher than in the control group. Moreover, multivariate analysis revealed that PNP is the strongest predictor of severe RLS in COPD patients.

Previous studies have demonstrated that PNP is common in patients with COPD, and that neuropathy increases with hypoxia. ${ }^{11-16}$ On the other hand, PNP is one of factors associated with RLS. ${ }^{3}$

Kaycan et al investigated neurophysiological changes in the peripheral and central nervous systems in COPD patients with moderate to severe hypoxemia, and found that airway obstruction and long-lasting COPD may not only cause PNP, but also affect the ponto-medullary portion of the brain by altering blood gases, resulting in hypoxemia, hypercapnia, and respiratory acidosis. ${ }^{11}$

The exact cause of RLS is still unknown. However, the dramatic therapeutic effect of dopaminergic agents supports the hypothesis that RLS is the result of a malfunction in the central, rather than the peripheral, nervous system. ${ }^{3}$ In electrophysiological studies investigating the pathophysiological role of the peripheral nervous system, tibial and median nerve stimuli responses were normal, revealing that primary sensorimotor disorders are not involved in RLS. ${ }^{10}$ The triggering of RLS in patients with PNP may induce the pathological activation of movement generators, which may have a lower threshold due to neurochemical disturbances. These generators are most probably situated in the formatio reticularis or in spinal dopaminergic cells. ${ }^{3}$

These data suggest the posibility that the central nervous system affects in severe COPD patients with PNP, particularly the brain- stem, and may have subsequent effects related to RLS pathophysiology in COPD patients.

However, in 24 of 39 RLS patients, PNP and any other diseases related to RLS were absent. In our multivariate models, we found that hypercapnia was predictive of both mild and severe RLS in COPD patients; however, the relationship between RLS and hypercapnia or hypoxia is unclear in the literature. 
The effects of hypercapnia and hypoxia on the central nervous system has been examined by measuring brain-stem auditory evoked responses (BAERs). In dogs, Kajimoto et al detected a transient increase in the amplitude of all the BAERs, which preceded the prolongation of latency, in response to hypoxia. ${ }^{17}$ Friss et al demonstrated significant prolongations of BAER wave $V$ and the interpeak interval III- $V$ in preterm infants in a hypercarbic state. ${ }^{18}$ In so far as prolonged latencies are thought to be due to impaired nerve conduction velocity or synaptic efficiency, they speculated that such changes indicated that hypercarbia had a deleterious effect on neuronal function. We speculate that hypercapnia and/or hypoxia, even without PNP, may be related to RLS pathophysiology in COPD patients as a trigger or initiating factor for RLS development in the central nervous system.

Our study had several limitations. First, we did not establish a causal mechanism between RLS and COPD, and we did not evaluate possible changes due to hypoxia or hypercapnia in RLS-related regions of the central nervous system, using neurophysiological methods or neuroradiological images. Second, we did not perform electromyography or nerve conduction studies in our patients. Instead, our analysis was mainly based on clinical data. In both patient and control groups, the actual number of cases with possible electrophysiologically detectable PNP may be higher than that found in our study. Third, abnormal cerebral iron metabolism is implied in all forms of RLS, ${ }^{19}$ but there were no significant differences in serum iron levels between our study groups and we did not collect data regarding central iron metabolism. Fourth, our patients were greater than 60 years old. Because advanced age is a risk factor for RLS, age itself may have contributed to the observed high prevalence of RLS.

To the best of our knowledge, this is the first study to explore the frequency and clinical features of RLS in patients with COPD, and we believe that further comprehensive studies are required.

In summary, we can conclude that RLS is frequent in COPD patients, particularly in patients with severe hypoxemia/ hypercapnia and in late stages of the disease. In addition, COPD can be added to the list of secondary causes of RLS, along with anemia, uremia, pregnancy, and rheumatoid arthritis. We suggest that early diagnosis and treatment of RLS in COPD patients is very important for preventing morbidity and increasing quality of life.

\section{REFERENCES}

1. Gamaldo CE, Earley CJ. Restless legs syndrome: a clinical update. Chest. 2006;130(5): 1596-604.

2. Glasauer FE. Restless legs syndrome. Spinal Cord. 2001;39(3): 125-33.

3. Rijsman RM, de Weerd AW. Secondary periodic limb movement disorder and restless legs syndrome. Sleep Med Rev. 1999; 3(2):147-58

4. Senior RM, Shapiro SD. Chronic obstructive pulmonary disease: epidemiology, pathophysiology, and pathogenesis. In: Fishman AP, editor. Fishman's pulmonary disease and disorders. New York: McGraw-Hill Book Company; 1998. p. 659-82.

5. Spillane JD. Restless legs syndrome in chronic pulmonary disease. Br Med J. 1970;4(5738):796-8.

6. Banno K, Delaive K, Walld R, Kryger MH. Restless legs syndrome in 218 patients: associated disorders. Sleep Med. 2000;1(3): $221-9$.
7. Allen RP, Picchietti D, Hening WA, Trenkwalder C, Walters AS, Montplaisir J. Restless legs syndrome: diagnostic criteria, special considerations, and epidemiology. A report from the restless legs syndrome diagnosis and epidemiology workshop at the National Institute of Health. Sleep Med. 2003;4(2):101-19.

8. Auger C, Montplaisir J, Duquette P. Increased frequency of restless legs syndrome in a French-Canadian population with multiple sclerosis. Neurology. 2005;65(10):1652-3.

9. Pauwels RA, Buist AS, Ma P, Jenkins CR, Hurd SS. GOLD Scientific Committee. Global strategy for the diagnosis, management, and prevention of chronic obstructive pulmonary disease: National Heart, Lung, and Blood Institute and World Health Organization Global Initiative for Chronic Obstructive Lung Disease (GOLD): executive summary. Respir Care. 2001;46(8):798-825.

10. Mosko SS, Nudleman KL. Somatosensory and brainstem auditory evoked responses in sleep-related periodic leg movements. Sleep. 1986;9(3):399-404.

11. Kayacan O, Beder S, Deda G, Karnak D. Neurophysiological changes in COPD patients with chronic respiratory insufficiency. Acta Neurol Belg. 2001;101(3):160-5.

12. Poza JJ, Marti-Masso JF. Peripheral neuropathy associated with chronic obstructive pulmonary disease. Neurologia. 1997;12(9): 389-94.

13. Jarratt JA, Morgan CN, Twomey JA, Abraham R, Sheaff PC, Pilling $\mathrm{JB}$, et al. Neuropathy in chronic obstructive pulmonary disease: a multicentre electrophysiological and clinical study. Eur Respir J. 1992;5(5):517-24.

14. Pfeiffer G, Kunze K, Bruch M, Kutzner M, Ladurner G, Malin JP, et al. Polyneuropathy associated with chronic hypoxaemia: prevalence in patients with chronic obstructive pulmonary disease. J Neurol. 1990;237(4):230-3.

15. Nowak D, Bruch M, Arnaud F, Fabel H, Kiessling D, Nolte D, et al. Peripheral neuropathies in patients with chronic obstructive pulmonary disease: a multicenter prevalence study. Lung. 1990;168(1):43-51.

16. Faden A, Mendoza E, Flynn F. Subclinical neuropathy associated with chronic obstructive pulmonary disease: possible pathophysiologic role of smoking. Arch Neurol. 1981;38(10): 639-42.

17. Kajimoto S, Hosomi H, Suwaki H, Hosokawa K. High-rate sequential sampling of auditory brain-stem and somatosensory evoked responses in hypoxia. Electroencephalogr Clin Neurophysiol. 1994;92 (5):456-61.

18. Friss HE, Wavrek D, Martin WH, Wolfson MR. Brain-stem auditory evoked responses to hypercarbia in preterm infants. Electroencephalogr Clin Neurophysiol. 1994;90(5):331-6.

19. Allen RP, Earley CJ. Restless legs syndrome: a review of clinical and pathophysiologic features. J Clin Neurophysiol 2001;18(2): $128-47$. 